\title{
THE EFFECT OF Sn ON Pt/C CATALYSTS FOR THE METHANOL ELECTRO-OXIDATION
}

\author{
T. Frelink, W. Visscher and J. A. R. VAN VeEN \\ Laboratory for Inorganic Chemistry and Catalysis, Eindhoven University of Technology, P.O. Box 513, \\ Eindhoven, The Netherlands
}

(Received 4 October 1993; accepted 17 January 1994)

\begin{abstract}
The effect of $\mathrm{Sn}$ for the methanol oxidation in sulfuric acid is investigated using electrodeposited Pt and carbon supported Pt. The preparation has a considerable influence, as the Sn effects range from a small increase to a decrease in methanol oxidation activity. Sn is believed to act through the activation of $\mathrm{H}_{2} \mathrm{O}$. The optimum $\mathrm{Sn}$ surface coverage is found to be low; of the order of $10 \%$.
\end{abstract}

Key words: electrocatalysis, methanol, $\mathrm{Pt}, \mathrm{Pt} / \mathrm{C}$, promotion by $\mathrm{Sn}$.

\section{INTRODUCTION}

The direct methanol fuel cell has been designated as a candidate for electric power sources. Since an acid electrolyte is preferred, the choice of the anode is confined to $\mathrm{Pt}$. The performance of $\mathrm{Pt}$ for the methanol oxidation is still rather poor, but it is possible to enhance its activity by introducing a second metal, like $\mathrm{Ru}$ or $\mathrm{Sn}$. Ru has been shown to be a good promotor[1, 2]. For Sn the effect is not yet clear. In early papers $[3,4]$ large enhancement factors $(50-100)$ were claimed for smooth and electrodeposited Pt on which Sn was deposited. Later, other authors found considerably smaller and sometimes even negative effects[5-8]. The positive effect of $\mathrm{Sn}$ is mainly attributed to activation of adsorbed $\mathrm{H}_{2} \mathrm{O}$, that is, $\mathrm{Sn}$ is responsible for the deliverance of an oxygen atom to the methanol adsorbate to oxidize it to $\mathrm{CO}_{2}$. Another explanation is the ligand effect, ie $\mathrm{Sn}$ influences the Pt-oxide formation or the Pt-adsorbate binding. The effect of $\mathrm{Sn}$ for carbon supported Pt catalysts is substantially lower (ca. 10). Moreover the influence of $\mathrm{Pt}$ particle size on the effect of Sn is not yet clear. A complicating fact in the comparison of the literature data is the large variety in preparation methods, which might be the cause of the different results.

The aims of the present paper are to: (i) explore whether variations in the way in which $\mathrm{Sn}$ is incorporated in the Pt catalyst do indeed lead to variations in its effect on the methanol oxidation activity of $\mathbf{P t}$ based electrodes; and (ii) find out whether any positive effects are in fact consistent with the view of $\mathrm{H}_{2} \mathrm{O}$ activation, taking into account that we and others have found that a carbon-based Pt catalyst with $\sim 4 \mathrm{~nm}$ particles already appear to have optimum $\mathrm{H}_{2} \mathrm{O}$ activation ability $[9,10]$.

\section{EXPERIMENTAL}

\section{Catalyst preparation}

Electrodeposited $\mathrm{Pt}$ was prepared on a smooth $\mathbf{P t}$ electrode of $6 \mathrm{~cm}^{2}$, from a $2 \mathrm{~g} \mathrm{H}_{2} \mathrm{PtCl}_{6} / 100 \mathrm{ml}$ solu- tion with a current of $5 \mathrm{~mA} \mathrm{~cm}^{-2}$ for $15 \mathrm{~min}$. The real Pt surface area was $101 \mathrm{~cm}^{2}$ after electrodeposition, as measured from the hydrogen desorption area. Sn was added by immersing the electrode, which was electrochemically pre-covered with hydrogen, in $0.3 \mathrm{~g}^{-1} \mathrm{SnO}$ in $36 \% \mathrm{KOH}$ at $80^{\circ} \mathrm{C}$.

All carbon supported catalysts were prepared with Vulcan XC-72R $\left(325 \mathrm{~m}^{2} \mathrm{~g}^{-1}\right)$ (Cabot) as support. Three different catalysts were used.

(A) Colloidal $\mathrm{Pt} / \mathrm{C}$ was prepared by reducing $\mathrm{H}_{2} \mathrm{PtCl}_{6}$ (Drijfhout) with sodium-citrate solution under reflux[11]. The obtained $\mathrm{Pt}$ sol was then added to the suspended carbon support. After filtration, the filtrate was found to be colourless, indicating that all Pt was adsorbed on the support. The catalyst was thereafter washed and dried at $125^{\circ} \mathrm{C}$. TEM measurements showed that the mean Pt particle size is $c a .4 \mathrm{~nm}$. Sn was added to this catalyst by immersion of the electrode (which was previously kept at a potential of $E=-0.65 \mathrm{~V}$ vs. mse for $60 \mathrm{~s}$ ) in a solution of either $0.3 \mathrm{gl}^{-1} \mathrm{SnO}$ (Aldrich) in $36 \%$ $\mathrm{KOH}$ (Merck) at $80^{\circ} \mathrm{C}$, or an aqueous solution of $10 \mathrm{gl}^{-1} \mathrm{SnCl}_{4}$ at $23^{\circ} \mathrm{C}$. The amount of $\mathrm{Sn}$ on the electrode was varied by varying the adsorption time.

(B) $\mathrm{PtSn}$ sol was prepared by adding $\mathrm{SnCl}_{2}$ (Aldrich) to a boiling solution of $\mathrm{H}_{2} \mathrm{PtCl}_{6}$ and sodium-citrate in water, in a stoichiometry of $\mathrm{Pt}: \mathrm{Sn}$ 10:1. The PtSn sol was adsorbed on the carbon support and the catalyst was then filtered, washed and dried at $125^{\circ} \mathrm{C}$.

(C) Impregnated $\mathrm{PtSn} / \mathrm{C}$ was prepared by mixing the carbon support with a dissolved 5:1 Pt-Sn chloride complex, this compound is used in the colorimetric detection of $\mathrm{Pt}[12]$. The mixture was boiled for $2 \mathrm{~h}$; formaldehyde (Merck) was then added as a reductor. After one more hour of reflux the catalyst was filtered, washed with water and dried at $125^{\circ} \mathrm{C}$.

\section{Electrode preparation}

The electrodes of the carbon supported Pt catalysts were prepared by pressing a mixture of the catalyst and a Teflon suspension on a Pt current collector. The electrode was dried at $125^{\circ} \mathrm{C}$ and sintered 


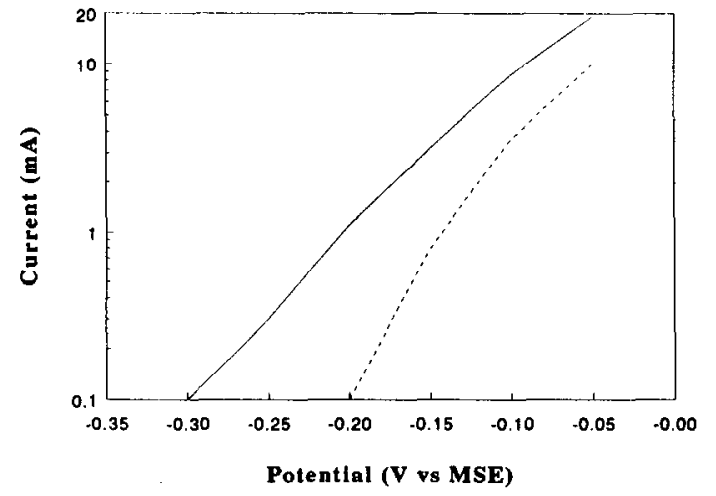

Fig. 1. Methanol oxidation activity of electrodeposited Pt before and after $\mathrm{Sn}$ immersion for the methanol oxidation: (-) Pt-Sn; (-..-) Pt. 0.5 M H $\mathrm{SO}_{4}, 0.1 \mathrm{M} \mathrm{CH}{ }_{3} \mathrm{OH}$.

at $340^{\circ} \mathrm{C}$ for $2 \mathrm{~h}$. The final Teflon content of all electrodes was ca. $20 \%$.

\section{Electrochemical characterization}

The catalyst surfaces were characterized by cyclic voltammetry at room temperature using a computer controlled Autolab potentiostat (Eco chemie). Potentiodynamic cycling was generally carried out between -0.65 and $+0.6 \mathrm{~V}$ vs. $m s e(E=0.65 \mathrm{~V}$ vs. rhe) in $0.5 \mathrm{M} \mathrm{H}_{2} \mathrm{SO}$. A $\mathrm{Pt}$ sheet was used as a
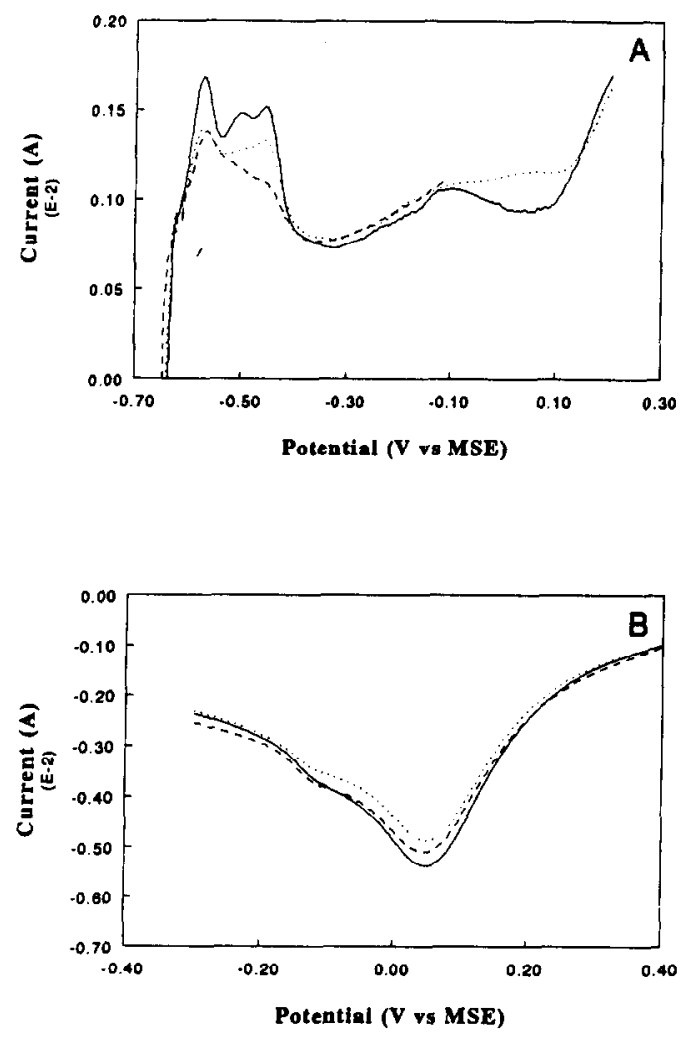

Fig. 2. The effect of Sn coverage on the cyclic voltammogram of $\mathrm{Pt} / \mathrm{C}$ catalyst $\mathrm{A}$. (A) Hydrogen desorption area: $\left(-\mathrm{Pt} / \mathrm{C} ;(\cdots) \theta_{\mathrm{Sn}}=0.26 ;(\cdots)\right) \theta_{\mathrm{Sn}}=0.13$. (B) Oxide reduction area: $\left.(-) \mathrm{Pt} / \mathrm{C} ;(-\cdots) \theta_{\mathrm{Sn}}=0.20 ;(\cdots)\right) \theta_{\mathrm{Sn}}=$ $0.30 .0 .5 \mathrm{M} \mathrm{H}_{2} \mathrm{SO}_{4}, v=10 \mathrm{mV} \mathrm{s}^{-1}$.

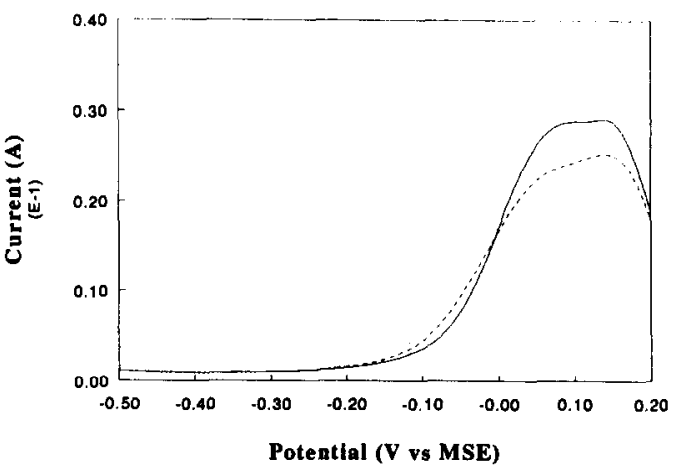

Fig. 3. Effect of Sn coverage on the oxidation of methanol on a $\mathrm{Pt} / \mathrm{C}$ catalyst $\mathrm{A}:(-) \theta_{\mathrm{Sa}}=0 ;(\ldots) \theta_{\mathrm{Sn}}=0.26$;

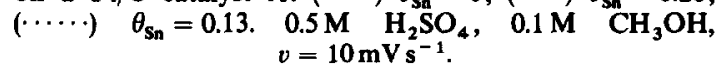

counter electrode. $\mathrm{Pt}$ surface areas and $\mathrm{Sn}$ surface coverages were determined from the hydrogen desorption area of the anodic cyclic voltammetric sweep assuming that $1 \mathrm{~cm}^{2}$ of $\mathrm{Pt}$ required $210 \mu \mathrm{C}[13]$.

The methanol oxidation was measured in $0.1 \mathrm{M}$ $\mathrm{CH}_{3} \mathrm{OH}$ (Merck)/0.5 M $\mathrm{H}_{2} \mathrm{SO}_{4}$ with a potential sweep with a sweep rate of $5 \mathrm{mV} \mathrm{s}^{-1}$; it was established that no significant different results were obtained with lower sweep rates. The change in activity will be compared for each catalyst with the Sn-free electrode.

Differential electrochemical mass spectroscopy measurements were carried out in the same electrolytes with an experimental setup similar to that of Vielstich et al.[14].

\section{RESULTS}

\section{Electrodeposited Pt}

Immersion (during $15 \mathrm{~min}$ ) of electrodeposited $\mathbf{P t}$ resulted in a $\mathrm{Sn}$ coverage of $20 \%$. The effect of this Sn coverage on the oxidation of methanol is shown in Fig. 1. In the low potential region the methanol oxidation activity is a factor 10 larger in the presence of Sn. This is in good agreement with the results of Iwasita et al.[15] who found an enhancement with a factor of 7.5. It is however substantially smaller than the 100 -fold increase at $-0.15 \mathrm{~V}$ found by Janssen and Moolhuysen[3]. It is further relevant to note that, also in contrast to their results, Sn does not influence the position of the $\mathrm{Pt}-\mathrm{O}$ reduction peak. By varying the immersion time of the electrodeposited $\mathrm{Pt}, \mathrm{Sn}$ coverages ranging up to $100 \%$ were obtained. Measurements of the activity as a function of $\mathrm{Sn}$ surface coverage show that high $\mathrm{Sn}$ coverages $(>50 \%)$ give a decrease in activity in the low potential region, whereas $\mathrm{Sn}$ coverages below $50 \%$ give an increase in activity. The optimum $\mathrm{Sn}$ coverage is below $20 \%$.

\section{Catalyst $A$}

Figure 2A shows the cyclic voltammogram of the $\mathrm{Pt} / \mathrm{C}$ catalyst $(\mathrm{A})$ as prepared and after $\mathrm{Sn}$ immersion. The hump at $c a$. $0 \mathrm{~V}$ indicates oxidates of $\mathrm{Sn}$ and no change in the Pt-oxide reduction is observed 
(Fig. 2B). By comparing the anodic hydrogen area it is seen that $\mathrm{Sn}$ preferentially covers the sites that strongly bind hydrogen. The $\mathrm{Sn}$ coverages for two different samples were calculated to be $\theta_{\mathrm{Sn}}=0.26$ and $\theta_{\mathrm{Sn}}=0.13$. The effect of these $\mathrm{Sn}$ coverages on the oxidation of methanol is shown in Fig. 3. In the potential region between -0.2 and $0 \mathrm{~V}$ the activity is increased, the catalyst with $13 \%$ Sn has the highest activity. At higher potentials however the activity is lower than that of pure $\mathrm{Pt} / \mathrm{C}$. This confirms that already at low coverage $\mathrm{Sn}$ can also act as a surface blocking agent vis-à-vis methanol adsorption[3].

Immersion in $\mathrm{SnCl}_{4}$ solutions always resulted in a Sn coverage higher than $50 \%$. At this high $\mathrm{Sn}$ coverage still some enhancement in methanol oxidation activity was found in the low potential region. DEMS measurements showed that the $\mathrm{CO}_{2}$ production during the methanol oxidation is indeed somewhat higher and starts at a lower potential (Fig. 4). Similar results were obtained for $\mathrm{CO}$ oxidation.
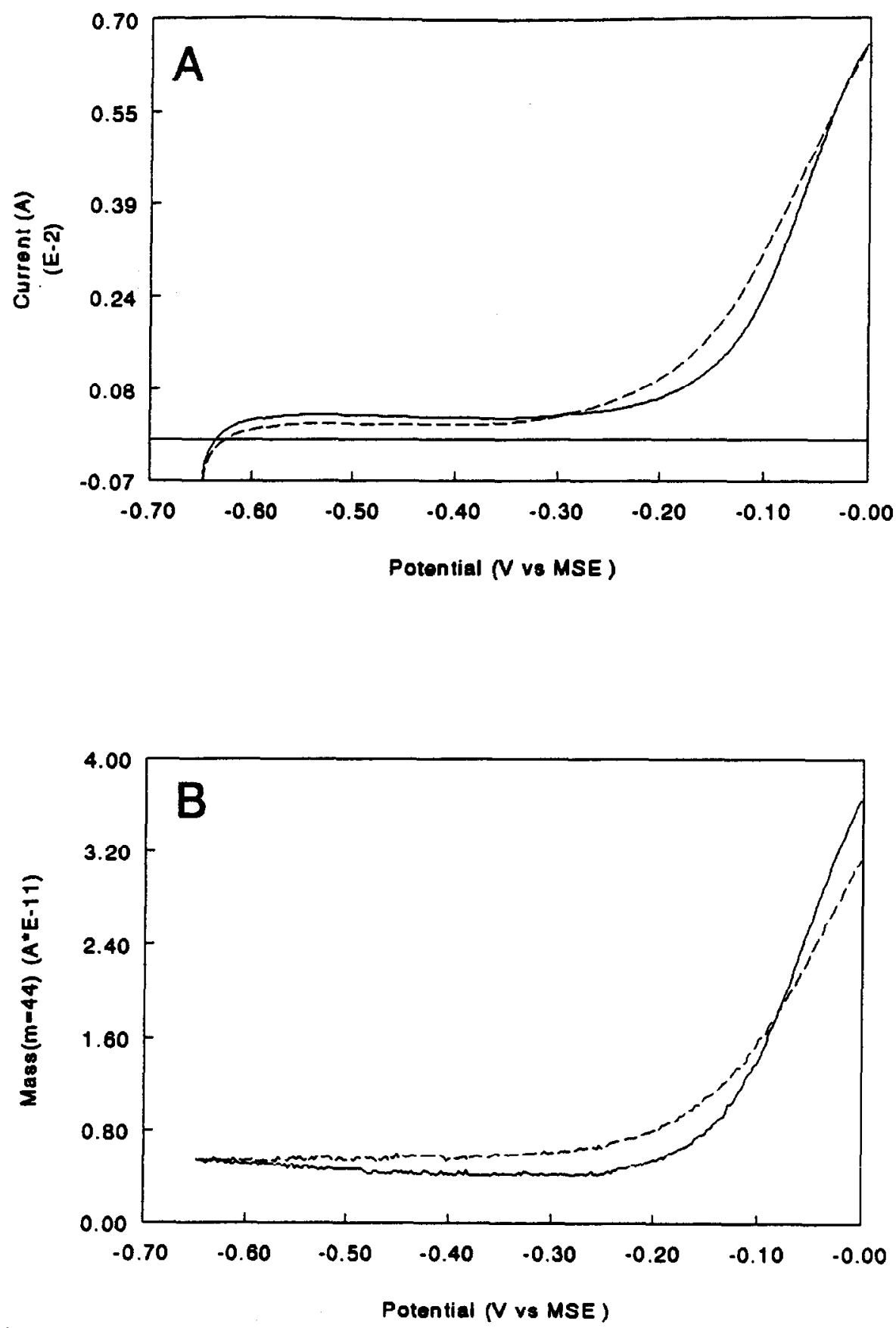

Fig. 4. Effect of high Sn coverage on the methanol oxidation: (A) Current potential curve; (B) mass potential curve. $(\longrightarrow) \theta_{\mathrm{Sn}}=0 ;(-\cdots) \theta_{\mathrm{sn}}=0.5 .0 .5 \mathrm{M} \mathrm{H}_{2} \mathrm{SO}_{4}, 0.1 \mathrm{M} \mathrm{CH}_{3} \mathrm{OH}, v=5 \mathrm{mV} \mathrm{s}^{-1}$. 
Oxidation of a pre-adsorbed species (either from $\mathrm{CO}$ or $\mathrm{CH}_{3} \mathrm{OH}$ ) gives a cathodic shift of approximately $0.1 \mathrm{~V}$ in $\mathrm{CO}_{2}$ production potential, as is shown in Fig. 5, again indicating that $\mathrm{Sn}$ promotes the oxidation of the adsorbed residue but also hampers the methanol adsorption.

\section{Catalyst $B$}

XPS measurement of the colloidal PtSn/C catalyst $B$ shows the presence of mainly Pt metal, with a small amount of oxidized species; the Sn spectra show that only oxidized $\mathrm{Sn}$ is present. The $\mathrm{Pt}: \mathrm{Sn}$ ratio was found to be $8: 1$. The cyclic voltammogram of this catalyst with and without $\mathrm{Sn}$ is given in Fig. 6A. No change in the $\mathrm{Pt}$-oxide reduction potential occurs. The $\mathrm{Sn}$ oxidation is observed at $c a$. $0 \mathrm{~V}$. Upon cycling of the electrode the $\mathrm{Sn}$ peak diminishes, indicating that $\mathrm{Sn}$ disappears from the surface. This is also indicated by an increase of the anodic hydrogen area. No preference for strongly bonded hydrogen is seen for this catalyst. As soon as the $\mathbf{S n}$ oxidation peak was no longer observed and the hydrogen area did not increase any further, we assumed that the surface was free of Sn, so that the electrode surface could be established. Estimation of the Sn surface coverage is difficult since we have found [9] that Pt particles on a carbon support grow during extensive cycling. However, if it is assumed that there is no particle growth, we estimated an $\mathbf{S n}$ coverage of at least $\theta_{\mathrm{Sn}}=0.07$, which is close to the $\mathrm{Pt}: \mathrm{Sn}$ ratio determined with XPS. This suggests that there is no strong Sn enrichment of the PtSn particle surface.

The methanol oxidation activity on $\mathrm{PtSn} / \mathrm{C}$ as given in Fig. 6B is about a factor 2 higher than on the catalyst free of $\mathrm{Sn}$.

\section{Catalyst $C$}

XPS measurements of the impregnated catalyst show Pt metal with a relatively large amount of oxi-
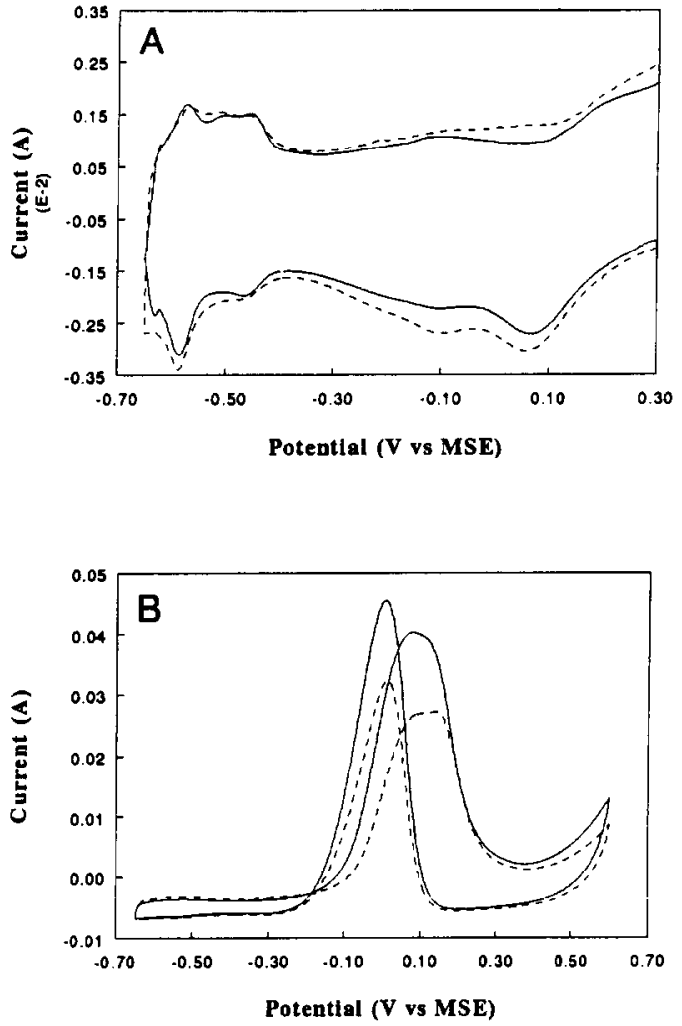

Fig. 6. (A) Cyclic voltammogram of colloidal PtSn/C catalyst B: (-) Pt/C; (---) PtSn/C, $0.5 \mathrm{M} \mathrm{H}_{2} \mathrm{SO}_{4}$. (B) Methanol oxidation on colloidal $\mathrm{PtSn} / \mathrm{C}$ catalyst $\mathrm{B}$. (-) $\mathrm{PtSn} / \mathrm{C} ;(\ldots) \mathrm{Pt} / \mathrm{C}, 0.5 \mathrm{M} \mathrm{H}_{2} \mathrm{SO}_{4} ; 0.1 \mathrm{M} \mathrm{CH} \mathrm{CH}_{3} \mathrm{OH}$, $v=10 \mathrm{mVs}^{-1}$.

dized species; the Sn spectra show the presence of an oxidized $\mathrm{Sn}$ species. The ratio of $\mathrm{Pt}: \mathrm{Sn}$ is found to be $4: 3$, which implies a very strong Sn enrichment of the surface. No oxidation peak for $S n$ could be

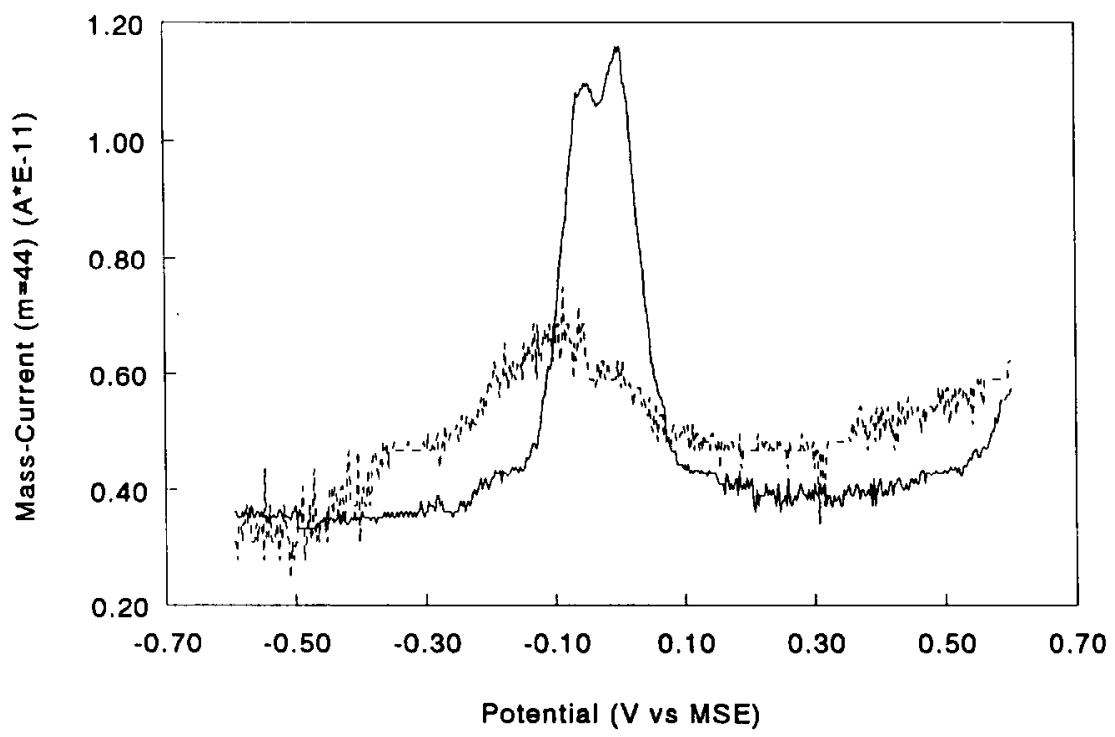

Fig. 5. Effect of Sn coverage on the oxidation of adsorbed CO. Mass-potential curve: $(-) \theta_{\mathrm{Sn}}=0$; $(\cdots \cdots) \theta_{\mathrm{Sn}}=0.48 .0 .5 \mathrm{M} \mathrm{H}_{2} \mathrm{SO}_{4}, v=5 \mathrm{mV} \mathrm{s}^{-1}$. 


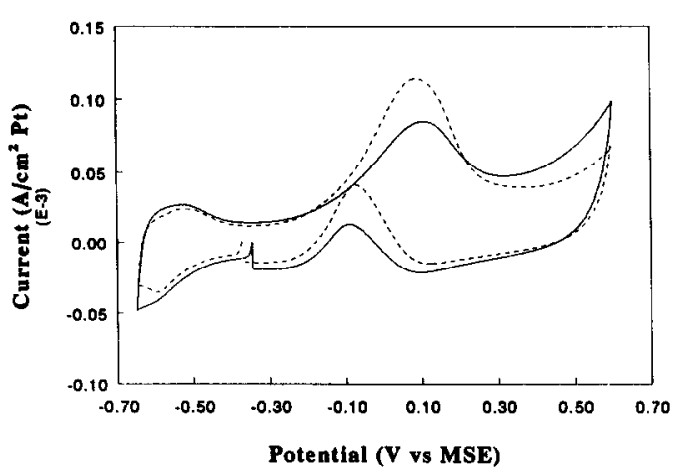

Fig. 7. Methanol oxidation on impregnated PtSn catalyst C: $(\longrightarrow) \mathrm{PtSn} / \mathrm{C}$; (-.-) Pt/C. $0.5 \mathrm{M} \mathrm{H} \mathrm{H}_{2} \mathrm{SO}_{4}, 0.1 \mathrm{M}$ $\mathrm{CH}_{3} \mathrm{OH}, v=10 \mathrm{mVs}^{-1}$.

detected by the cyclic voltammogram of this catalyst. Upon cycling however the hydrogen area increased like for catalyst $B$ and the methanol oxidation activity reached a value representative of an impregnated catalyst without $\mathrm{Sn}$ [9].'The methanol oxidation was found to be lower than for the Sn free catalyst (Fig. 7).

\section{GENERAL DISCUSSION}

No change in the $\mathrm{Pt}$-oxide reduction potential is observed in the presence of Sn for any of the Pt catalysts. Sn does not seem to influence the Pt-oxide formation and a ligand effect of Sn therefore is not very likely.

For the purpose of this discussion the methanol oxidation can be written as:

$$
\begin{gathered}
\mathrm{CH}_{3} \mathrm{OH} \rightarrow \mathrm{mOH}+3 \mathrm{H}^{+}+3 \mathrm{e}^{-}, \\
\mathrm{H}_{2} \mathrm{O} \rightarrow-\mathrm{OH}+\mathrm{H}^{+}+\mathrm{e}^{-}, \\
=\mathrm{COH}+-\mathrm{OH} \rightarrow \mathrm{CO}_{2}+2 \mathrm{H}^{+}+2 \mathrm{e}^{-} .
\end{gathered}
$$

We take $\mathrm{Sn}$ to promote the activation of water, equation (2), which proceeds difficultly on Pt itself. A secondary effect of $\mathrm{Sn}$ is to impede the methanol adsorption, hence the optimal $\mathrm{Sn}$ coverage must be low. Evidence exists that $\mathrm{Sn}$ covers two Pt sites[16], whereas methanol needs an ensemble of 5-6 Pt sites. The amount of these ensembles rapidly decreases with an increasing $\mathrm{Sn}$ coverage. This explains why at high Sn surface coverages, where a cathodic shift of $0.1 \mathrm{~V}$ for the oxidation of an adsorbate is observed, the steady-state activity is still low (low rate of formation of the adsorbate). The enhancement in methanol oxidation activity is highest for the electrodeposited $\mathrm{Pt}$, where the $\mathrm{H}_{2} \mathrm{O}$ activation is most difficult. The activity of the $\mathrm{Sn}$ promoted $\mathrm{Pt}$ is higher than that of $\mathrm{Sn}$-free colloidal $\mathrm{Pt}$ with optimum particle size, if compared per real surface area.

The enhancement in the case of colloidal $\mathbf{P t}$, with Pt particles of $c a .4 \mathrm{~nm}$, is still about a factor 2, indicating that Sn transfers its oxygen to the adsorbed residue at a higher rate than $\mathbf{P t}$. We observed that $\mathbf{P t}$ particles of $\sim 4 \mathrm{~nm}$ have an optimal water activation ability[9].
Impregnated Pt particles are known to be substantially smaller $(\sim 2 \mathrm{~nm})$ and thus "over-active" in water activation[9]. No enhancement, on the contrary, is found for the smallest Pt particles. This over-activity diminishes the amount of free adsorption sites for methanol, addition of Sn will only decrease this amount further and thus lower the methanol oxidation activity. This could explain the decrease in activity for the impregnated PtSn catalyst, but incomplete reduction of the catalyst might also be of influence, as XPS spectra show higher oxidation states for $\mathbf{P t}$ and $\mathrm{Sn}$ in the impregnated catalyst. The fact that XPS measurements show a high amount of Sn $(\sim 40 \%)$ should not be of any influence, as with immersed electrodes $\mathrm{Sn}$ coverages as high as $50 \%$ still show a small enhancement in activity.

\section{CONCLUSION}

It appears that different preparation methods may indeed account for the different results on the effect of Sn. A Pt particle size effect may play a role as well. There is no indication that Sn acts via a ligand effect, a water activation effect seems to be most likely.

\section{REFERENCES}

1. T. Iwasita, F. C. Nart and W. Vielstich, Ber. Bunsenges. Phys. Chem. 94, 1030 (1990).

2. A. Hamnett, B. J. Kennedy and F. E. Wagner, J. Catal. $124,30(1990)$.

3. M. M. P. Janssen and J. Moolhuysen, Electrochim. Acta 21, 861 (1976).

4. S. Motoo and M. Watanabe, J. electroanal. Chem. 69, 429 (1976).

5. M. Watanabe, Y. Furuchi and S. Motoo, J. electroanal. Chem. 191, 367 (1985).

6. S. R. Wang and P. S. Fedkiw, J. electrochem. Soc. 139, 3151 (1992).

7. B. Bittins-Cattaneo and T. Iwasita, J. electroanal. Chem. 238, 151 (1987).

8. S. A. Campbell and R. Parsons, J. Chem. Soc., Faraday Trans. 88, 833 (1992).

9. T. Frelink, W. Visscher and J. A. R. van Veen, to be published.

10. P. A. Attwood, B. D. McNicol and R. T. Short, J. appl. Electrochem. 10, 213 (1980).

11. K. Aika, L. L. Ban, I. Okura, S. Namba and J. Turkevich, J. Res. Inst. Catalysis Hokkaido Univ. 24, 54 (1976).

12. A. S. Meyer and G. H. Ayres, J. Am. Chem. Soc. 77, 2671 (1955)

13. T. Biegler, D. A. J. Rand and R. Woods, J. electroanal. Chem. 29, 269 (1971).

14. T. Iwasita, W. Vielstich and E. Santos, J. electroanal. Chem. 229, 367 (1987).

15. T. Iwasita-Vielstich, in Advances in Electrochemical Science and Engineering (Edited by $\mathrm{H}$. Gerischer and $\mathrm{C}$. W. Tobias), Vol 1, pp. 127-170. VCH, New York (1990).

16. J. Sobkowski, K. Franaszcuk and A. Piasecki, J. electroanal. Chem. 196, 145 (1985). 